\title{
DEPRESSION, ANXIETY AND QUALITY OF LIFE OF CANCER SURVIVORS
}

\author{
Koijam Shantibala Devi', Laishram Jaichand Singh ${ }^{2}$, Naorem Rebika Devi3 , Elangbam Priyokumar Singh ${ }^{4}$ \\ ${ }^{1}$ Associate Professor, Department of Psychiatry, Jawaharlal Nehru Institute of Medical Sciences (JNIMS), Imphal, Manipur. \\ 2Professor, Department of Radiology, Regional Institute of Medical Sciences (RIMS), Imphal, Manipur. \\ 3Ph.D Scholar, Mizoram University. \\ ${ }^{4}$ M.Phil. Clinical Psychology, RIMS.
}

\section{ABSTRACT}

\section{BACKGROUND}

Cancer of any type is a serious and life-threatening illness, not uncommon in the general population. Cancer survivor can mean any person diagnosed with cancer from the time of initial diagnosis until his or her death. It includes people who are dying from untreatable cancer. Cancer survivor also includes those patients who are receiving or have received treatment with no active disease process and those who are not in the terminal stage of the illness. Cancer survivors tend to develop anxiety, depression and change in their quality of life as they have to make adjustment to many psychological and physical changes as well as financial constraint.

\section{MATERIALS AND METHODS}

Fifty (50) cancer survival patients visiting Department of Radiotherapy, Regional Institute of Medical Sciences (RIMS), Imphal, during February 2015 to December 2015 were enrolled in this study. The study forms including the questions regarding the patient's demographic characteristics, Becks Depression Inventory (BDI), State and Trait Anxiety Inventory (STAI) and WHOQOL BREF were completed during face-to-face interviews for the determination of the psychological status of the patients. And the data were analysed using SPSS version 20.0.

\section{RESULTS}

All the dimensions of the Quality of Life (QoL) except D3= Domain 3 (Social Relationship) are negatively correlated with both the sub-types of STAI (State and Trait Anxiety). The state anxiety score is negatively correlated with D1=Domain 1 (Physical health; $\mathrm{p}=.001$ ), D2 = Domain 2 (Psychological; $\mathrm{p}=.001$ ), D4= Domain 4 (Environment; $\mathrm{p}=.000$ ). Also, the trait anxiety scores of the patients are negatively correlated with D1=Domain 1 (Physical health; p=.001), D2= Domain 2 (Psychological; p=.000), D4= Domain 4 (Environment; $\mathrm{p}=.000$ ). However, there is no significant difference in terms of D3= Domain 3 (Social Relationship; state anxiety $\mathrm{p}=.142$ and trait anxiety $\mathrm{p}=.220$ ) and STAI scores. On the other hand, there is positive correlation between Becks Depression Inventory (BDI) and STAI ( $\mathrm{p}=.013)$. But there is negative correlation between BDI and quality of life (Domain 1, $p=.000$; Domain 2, $\mathrm{p}=.000$; Domain 3, $\mathrm{p}=.005$; Domain 4, $\mathrm{p}=.003$ ).

\section{CONCLUSION}

The study sample consists of 37 females and 13 males and majority of the sample belongs to the age group of 60-70. Most of the study sample are illiterate, married, housewife and live in a joint family. And maximum no. of the study samples have been suffering from illness from 2-5 years. This study finds a negative correlation between Quality of Life (QoL) and BDI and also with QoL and STAI. However, there is a positive correlation between BDI and STAI $(p=.013)$. Therefore, to improve the patient's overall health condition and adherence to cancer treatment. There is need for addressing the associated psychiatric problems too.

\section{KEYWORDS}

Cancer, Cancer Survivor, Anxiety, Depression, Quality of Life.

HOW TO CITE THIS ARTICLE: Devi KS, Singh LJ, Devi NR, et al. Depression, anxiety and quality of life of cancer survivors. J. Evolution Med. Dent. Sci. 2016;5(36):2077-2082, DOI: 10.14260/jemds/2016/488

\section{INTRODUCTION}

A cancer survivor is someone who is "living with or beyond cancer", someone who has completed initial cancer management and has no apparent evidence of active disease; is living with progressive disease and may be receiving cancer treatment, but is not in the terminal phases of illness; or has had cancer in the past. ${ }^{1}$

The National Coalition for Cancer Survivorship (NCCS). ${ }^{2}$ pioneered the definition of survivor as being any person diagnosed with cancer from the time of initial diagnosis until his or her death.

Financial or Other, Competing Interest: None.

Submission 17-03-2016, Peer Review 14-04-2016,

Acceptance 20-04-2016, Published 03-05-2016.

Corresponding Author:

Elangbam Priyokumar Singh,

Department of Clinical Psychology,

RIMS,

Imphal- 795004.

E-mail: elangpriyo1@gmail.com

DOI: $10.14260 /$ jemds $/ 2016 / 488$
This expansive definition of "survivor" includes people who are dying from untreatable cancer. NCCS. ${ }^{2}$ later expanded the definition of survivor even further to include family, friends and voluntary caregivers who are affected by the diagnosis in any way.

The need of psychological studies arises as substantial psychological distress has frequently been observed in people with chronic illness. And cancer is also considered as a serious and potentially life-threatening illness, cancer patients do experience a range of psychological and physical medical challenges. ${ }^{3}$ The main problems of long-term cancer survivors are in the areas of emotional and/or social support, health habits, spiritual/philosophical view of life and body image concerns. ${ }^{4}$

Cancer survivors struggle emotionally, needing to adjust to changes treatment has made to their body; have to cope with short-term and long-term side effects of their cancer or its treatment; have to live with the knowledge that their cancer cannot be cured, even though they feel healthy; 
have difficulties accessing information about their condition or any after-effects they may experience; struggle financially as the household income decreases; experience problems returning to the workplace.

The characteristics used to define anxiety disorders in the common diagnostic systems employed in psychiatry, i.e. the World Health Organization's International Classification of Disorders (ICD-10). 5 and the American Psychiatric Association's Diagnostic and Statistical Manual (DSM-IV).$^{6}$ are 1) Symptoms of autonomic over-activity which includes palpitation and sweating, 2) Anxious behaviours such as restlessness and reassurance-seeking, 3) Changes in thinking include apprehension, worry and poor concentration, and 4) Physical symptoms such as muscle tension or fatigue may occur.

In context of cancer patients, anxiety levels are found high soon after the onset of cancer symptoms during investigation and diagnosis, but many people adapt over time. These effects can vary from person to person, change over time and range in intensity from mild and intermittent to fully disabling disorder. However, the prevalence of anxiety problems after a cancer diagnosis falls over the following years. ${ }^{7}$ but may not return to population levels even with curative treatment. ${ }^{8}$ Therefore, it is well acknowledged that adults diagnosed with cancer are vulnerable to depression and anxiety.

In the general population, younger women are more prone to anxiety. ${ }^{9}$ However age, gender, marital status, social class and education are not associations consistently seen with anxiety in cancer patient populations. Comparisons within the general population, pathological anxiety are commoner in people with cancer than in those without any chronic medical condition. ${ }^{10}$ Between $15 \%$ and $40 \%$ of cancer patients develop clinical anxiety and/or depression.11-13 Even for those ostensibly cured, the prevalence remains appreciably higher than that of the general population a year or more after diagnosis. ${ }^{14}$

\section{Cancer Survivorship and Quality of Life}

"Cancer survivorship" is a term that has come to represent the state or process of living following a diagnosis of cancer, regardless of how long a person lives. It is a concept used by many health care professionals, researchers, and cancer patients to understand not only the physical but also the social, psychological and spiritual/existential impact of cancer on one's life and for the remainder of one's life. When viewed as a continual, dynamic and ever-changing process that begins at the moment of diagnosis and continues for the remainder of life, cancer survivorship can be defined as the experience of "living with, through or beyond cancer."15

World Health Organization (WHO). ${ }^{16}$ defines quality of life as individual's perceptions of their position in life in the context of the culture and value systems in which they live and in relation to their goals, expectations, standards and concerns. This definition reflects the view that quality of life refers to a subjective evaluation, which is embedded in a cultural, social and environmental context. Because this definition of quality of life focuses upon respondent's "perceived" quality of life, it is not expected to provide a means of measuring in any detailed fashion symptoms, diseases or conditions, but rather the effects of disease and health interventions on quality of life.

The term Quality of Life (QoL) is used to evaluate the general well-being of individuals and societies. According to the World Health Organization (WHO). ${ }^{16}$, Quality of Life (QoL) defined as individual perception of life, values, objectives, standards and interests in the framework of culture. A number of illness-related factors exist that can affect QoL. The amount of symptoms distress experienced by an individual has been related to QoL in a number of people with cancer. Cancer can produce many different symptoms, some subtle and some not at all subtle. Some symptoms of cancer affecting QoL in patients would be cancer type and stage as some types of cancer do not present any symptoms until they are in advanced stages, time since diagnosis, patient acceptance and intensity of the disease and the level of psychological distress experienced by caregivers.

\section{AIMS AND CONSENTING}

To assess depression, anxiety level and quality of life of cancer patients visiting radiotherapy department, RIMS after taking informed consent.

\section{AIM}

To assess depression, anxiety levels and quality of life of cancer patients visiting Department of Radiotherapy, RIMS, Imphal, using the Beck Depression Inventory (BDI), State and Trait Anxiety Inventory (STAI) and WHOQOL BREF.

\section{Inclusion}

1. Age between 20 years and 70 years.

2. Both male and female

3. Under cancer therapy for 1 year and above.

\section{Exclusion}

1. Patients below 20 years and above 70 years.

2. Patients under cancer treatment less than 1 year.

3. Patients with mental retardation and past history of any major mental illness.

\section{Informed Consent}

Verbal informed consent was taken from each patient after full explanation of the aims and objectives of the study.

\section{MATERIALS AND METHODS}

A total of 50 cancer survivors both inpatient and outpatient visiting Dept. of Radiotherapy, Regional Institute of Medical Sciences (RIMS), Imphal, during the period of Feb. 2015 to December 2015 are included in the present analysis. The psychological status of the patients is assessed on BDI, WHOQOL BREF and STAI.

State and Trait Anxiety Inventory (Form Y) is developed by psychologists Charles Spielberger, R.L. Gorsuch and R.E. Lushene. ${ }^{17}$ This self-report measure indicates the intensity of feelings of anxiety; it distinguishes between state anxiety (A temporary condition experienced in specific situations) and trait anxiety (A general tendency to perceive situations as threatening).

Items 1 - 20 measure situational or state anxiety (STAIS), and items 21 - 40 measure underlying or trait anxiety (STAI-T). Both scales are intended to form uni-dimensional measures. For the state items respondents are asked to indicate "How you feel right now, that is, at this moment." 
Responses indicate intensity of feeling on a 1 to 4 scale from "not at all" through "somewhat, moderately so" to "very much so." For the trait items, the question concerns "how you generally feel" and the response scale indicates frequency: "almost never," "sometimes," "often" and "almost always." After reversing scores for positively-worded items, total scores for state and trait are calculated, ranging from 20 - 80 .

Beck's depression scale (BDI) is a series of questions developed to measure the intensity, severity and depth of depression in patients with psychiatric disorders. BDI was developed in 1961 by Beck. ${ }^{18}$ and it composes 21 items, each with 4 possible responses. Each response is assigned a score ranging from zero to three indicating the severity of the symptom. Individual questions of the BDI assesses mood, pessimism, sense of failure, self-dissatisfaction, guilt, punishment, self-dislike, self-accusation, suicidal ideas, crying, irritability, social withdrawal, body image, work difficulties, insomnia, fatigue, appetite, weight loss, bodily preoccupation and loss of libido. Items 1 to 13 assess symptoms that are psychological in nature, while items 14 to 21 assess more physical symptoms. The standardized cut-offs used differ from the original: 0-13 (minimal depression), 1419 (mild depression), 20-28 (moderate depression) and 2963 (severe depression).

The WHOQOL BREF Field Trial Version. ${ }^{19}$ has been developed to provide a short form quality of life assessment that looks at Domain level profiles using data from the pilot WHOQOL assessment and all available data from the Field Trial Version of the WHOQOL-100. The WHOQOL-BREF contains a total of 26 questions. To provide a broad and comprehensive assessment, one item from each of the 24 facets contained in the WHOQOL-100 has been included. In addition, two items from the overall Quality of Life and General Health facet have been included. The WHOQOL-BREF should be self-administered if respondents have sufficient ability: otherwise, interviewer-assisted or interviewadministered forms should be used. Standardised instructions, given on the second page of the WHOQOL-BREF example assessment, should be read out to respondents in instances where the assessment is interviewer-administered.

\section{RESULTS}

\begin{tabular}{|l|c|c|}
\hline \multicolumn{1}{|c|}{ Characteristics } & $\begin{array}{c}\text { Patients } \\
\text { (N=50) }\end{array}$ & N \% \\
\hline Gender: & & \\
Male & 13 & 26 \\
Female & 37 & 74 \\
\hline Age Range: & & \\
$20-30$ & 4 & 8 \\
$30-40$ & 4 & 8 \\
$40-50$ & 12 & 24 \\
$50-60$ & 12 & 24 \\
$60-70$ & 18 & 36 \\
\hline Marital Status: & & \\
Married & & \\
Single (Widowed, Divorced, & 41 & 82 \\
Unmarried) & 9 & 18 \\
\hline
\end{tabular}

\begin{tabular}{|l|c|c|}
\hline Education: & 21 & 42 \\
High school & 10 & 20 \\
University level & 19 & 38 \\
Illiterate & & \\
\hline Occupation: & 26 & 52 \\
House Wife & 7 & 14 \\
Government Employee & 14 & 28 \\
Self-Employed & 3 & 6 \\
Student & & \\
& & \\
Monthly Income in Indian Rupee: & 23 & 46 \\
<10,000 & 20 & 40 \\
10,000-20,000 & 7 & 14 \\
20,000 and above & 18 & 36 \\
& 32 & 64 \\
\hline Family Type: & \multicolumn{2}{|}{} \\
Nuclear & 9 & 18 \\
Joint & 23 & 46 \\
\hline Duration of Illness: & 18 & 36 \\
1-2 Years & & \\
2-5 Years & & \\
5 Years and above & & \\
\hline Table 1: Socio-Demographic Characteristics of Patients \\
\hline
\end{tabular}
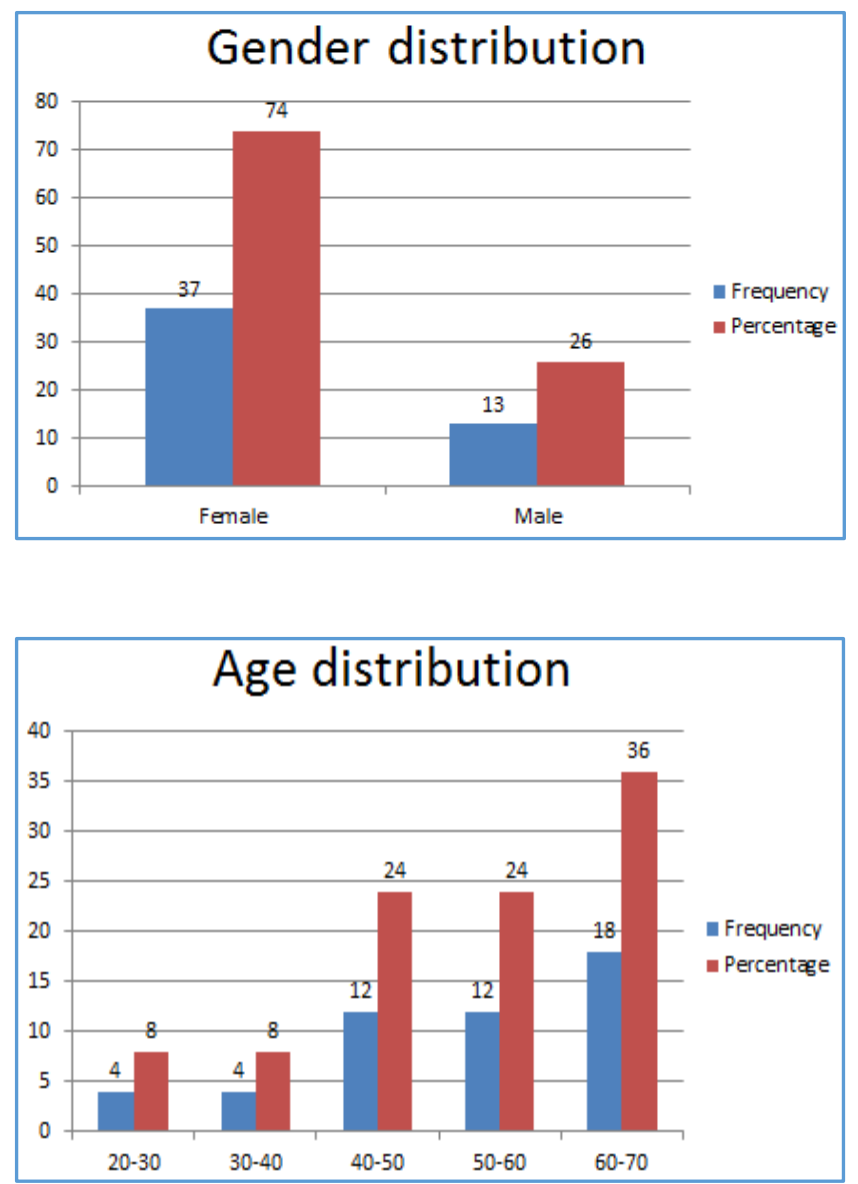

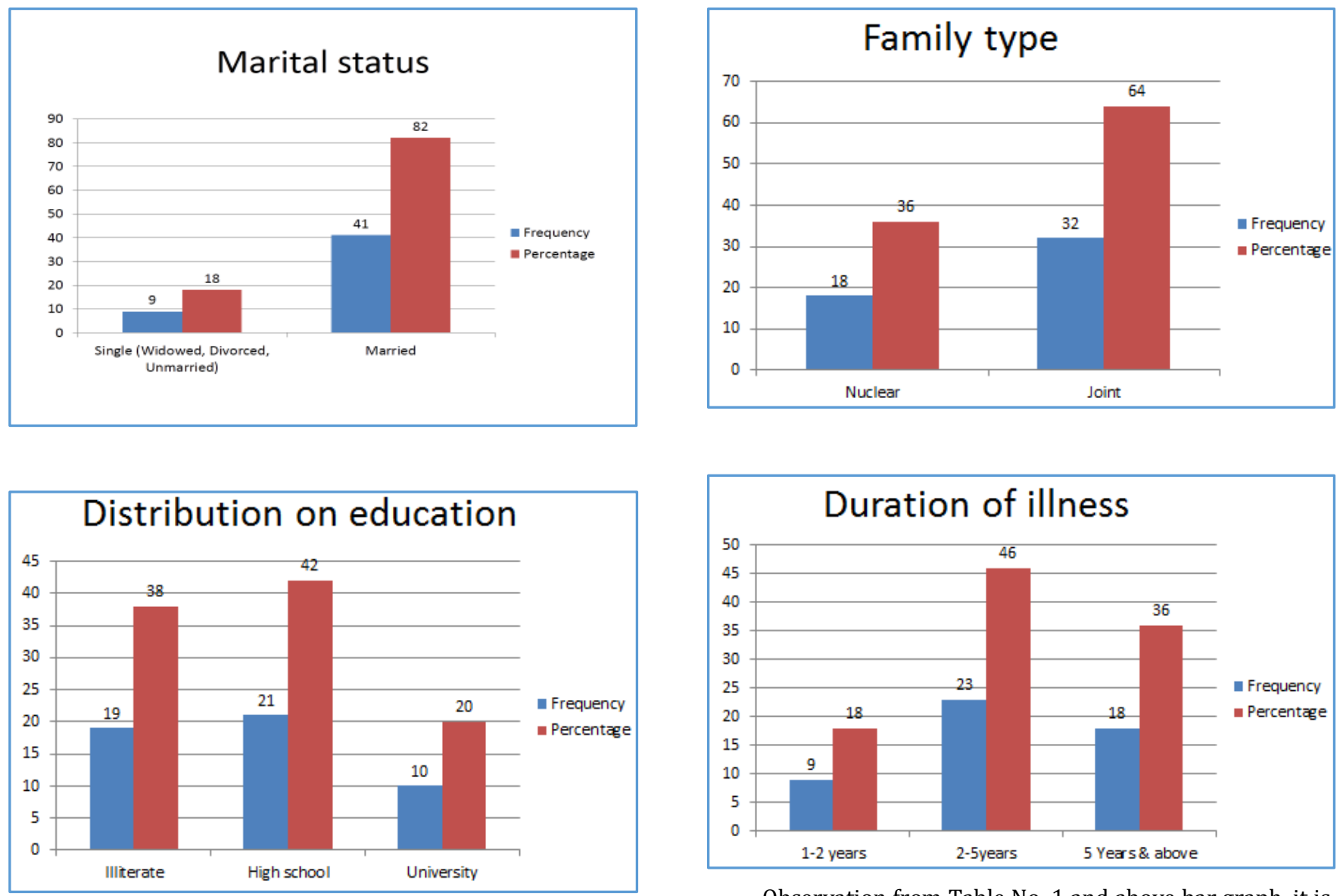

Observation from Table No. 1 and above bar graph, it is cleared that the study sample consists of $13(26 \%)$ males and 37 (74\%) females. Maximum number of the sample belongs to the age group of $60-70(36 \%, 18)$, age group of $20-30$ and $30-40$ represents only $8 \%$ (4) and $40-50$ and $50-60$ age group represents $24 \%$ (12). Further, 41 (82\%) out of total 50 cases are married and only $9(18 \%)$ cases are single (either unmarried or divorced or widowed). Maximum no. of the cases are educated up to high school $(21,42 \%)$, only 10 (20\%) are educated up to university level and rest 19 (38\%) are illiterate. Occupation wise distribution indicates that 26 $(52 \%)$ cases out of the total sample are housewives, 7 (14\%) are govt. employees, 14 (28\%) are self-employed and $3(6 \%)$ are students. And monthly income wise distribution shows that out of the total sample, $23(46 \%)$ cases earn below Rs. 10,000/, 20 (40\%) cases earn Rs. 10,000-20,000/ and rest 7 (14\%) cases earn above Rs. 20,000/. Further, 18 (36\%) of the total cases live in nuclear family, whereas rest of the sample i.e. $32(64 \%)$ of the cases live in joint family. And duration of the illness ranges from $2-5$ years $(23,46 \%), 5$ years and above $(18,36 \%)$ and $1-2$ years $(9,18 \%)$.

\begin{tabular}{|c|c|c|c|c|}
\hline Scales & BDI & $\begin{array}{c}\text { Pearson } \\
\text { Correlation }\end{array}$ & $\begin{array}{c}\mathbf{p} \\
\text { value }\end{array}$ & $\mathbf{N}=\mathbf{5 0}$ \\
\hline STAI & $\begin{array}{c}\text { State } \\
\text { anxiety }\end{array}$ & $.349^{*}$ & .013 & \\
\hline & $\begin{array}{c}\text { Trait } \\
\text { anxiety }\end{array}$ & $.347^{*}$ & .013 & \\
\hline $\begin{array}{c}\text { Quality of } \\
\text { life }\end{array}$ & D1 & $-.553^{* *}$ & .000 & \\
\hline & D2 & $-.480^{* *}$ & .000 & \\
\hline \multicolumn{7}{|c|}{} & D3 & $-.391^{* *}$ & .005 & \\
\hline & D4 & $-.418^{* *}$ & .003 & \\
\hline \multicolumn{2}{|c|}{ Table 2: Correlations between Beck Depression Inventory (BDI) } \\
\hline
\end{tabular}

and State-Trait Anxiety (STAI) \& Quality of Life Scale 
D1=Domain 1 (Physical health), D2= Domain 2 (Psychological), D3= Domain 3 (Social Relationship), D4= Domain 4 (Environment).

*. Correlation is significant at the 0.05 level (2-tailed).

**. Correlation is significant at the 0.01 level (2-tailed).

Table no. 2 shows that there is a positive correlation between BDI and STAI (state anxiety, $\mathrm{p}=.013$; trait anxiety, $\mathrm{p}=.013$ ). And there is negative correlation between BDI and quality of life (Domain 1, p=.000; Domain 2, p=.000; Domain $3, \mathrm{p}=.005$; Domain $4, \mathrm{p}=.003$ ).

\begin{tabular}{|c|c|c|c|c|}
\hline \multirow{2}{*}{ Scales } & \multicolumn{2}{|c|}{ Quality of Life } & & \\
\cline { 2 - 5 } & D1 & D2 & D3 & D4 \\
\hline State Anxiety & & & & \\
Pearson Correlation & $-.469^{* *}$ & $-.465^{* *}$ & -.211 & $-.482^{* *}$ \\
P Value & .001 & .001 & .142 & .000 \\
\hline Trait Anxiety & & & & \\
Pearson Correlation & $-.461^{* *}$ & $-.514^{* *}$ & -.177 & $-512^{* *}$ \\
P Value & .001 & .000 & .220 & .000 \\
\hline Table 3: Correlations between State-Trait \\
Anxiety (STAI) \& Quality of Life Scale \\
\hline
\end{tabular}

$\mathrm{N}=50$. D1=Domain 1 (Physical health), D2= Domain 2 (Psychological), D3= Domain 3 (Social Relationship), D4= Domain 4 (Environment)

*. Correlation is significant at the 0.05 level (2-tailed).

**. Correlation is significant at the 0.01 level (2-tailed).

In Table 3, the study sample is compared in terms of Quality of Life and STAI scores. Comparison on both scale shows that all the dimensions of the Quality of Life except D3= Domain 3 (Social Relationship) are negatively correlated with both the two sub-types of STAI. The state anxiety score is negatively correlated with D1=Domain 1 (Physical health; $\mathrm{p}=.001$ ), $\mathrm{D} 2=$ Domain 2 (Psychological; $\mathrm{p}=.001$ ), $\mathrm{D} 4=$ Domain 4 (Environment; $\mathrm{p}=.000$ ). And also the trait anxiety score of the sample is also negatively correlated with D1=Domain 1 (Physical health; $\mathrm{p}=.001$ ), D2= Domain 2 (Psychological; $\mathrm{p}=.000), \mathrm{D} 4=$ Domain 4 (Environment; $\mathrm{p}=.000$ ). However, there is no significant difference in terms of D3= Domain 3 (Social Relationship; state anxiety $\mathrm{p}=.142$ and trait anxiety $\mathrm{p}=.220$ ) and STAI scores.

\section{DISCUSSION}

The study finding shows a positive correlation between BDI and STAI (Both State and Trait anxiety) scores indicating the relations between the two entities. Other study also found that in comparisons within the general population, pathological anxiety is commoner in people with cancer than in those without any chronic medical condition. ${ }^{10}$ Further in a meta-analysis study, the prevalence of depression and anxiety were significantly higher in Chinese adults with cancer compared with those without. ${ }^{20}$ And other studies had also found that between $15 \%$ and $40 \%$ of cancer patients develop clinical anxiety and/or depression.11-13

On the other hand, a negative relation between BDI and Quality of Life is found signifying that level of depression directly affects the quality of life of the patients. And also the domains of the quality of life except Domain No. 3, i.e. social relationship are negatively correlated with state and trait anxiety. Anxiety levels significantly affect the patient's physical and psychological health and environment as well. A pattern of association between anxiety and self-reported quality of life, particularly impaired social functioning, fatigue and physical impairment, has been demonstrated in cancer care. ${ }^{21}$ The main problems of long-term cancer survivors are in the areas of emotional and/or social support, health habits, spiritual/philosophical view of life and body image concerns. ${ }^{4}$ However, finding of this study indicates that despite the anxiety level, social relationship of the patients seems to be maintained.

\section{LIMITATION}

The limitation of the study includes small sample size and unequal number of male and female cases.

\section{CONCLUSION}

The study sample consists of 13 males and 37 females. Age of the sample ranges from 20-70 and majority of the sample belongs to the age group of 60-70. Most of the study sample are illiterate, married, housewife and live in a joint family. Duration of illness ranges from 1-5 years and above and most of the study samples have been suffering from illness from 2 5 years.

All the dimensions of the Quality of Life except D3= Domain 3 (Social Relationship) are negatively correlated with both the sub-types of STAI. The state anxiety score is negatively correlated with D1=Domain 1 (Physical health; $\mathrm{p}=.001$ ), D2= Domain 2 (Psychological; $\mathrm{p}=.001$ ), D4= Domain 4 (Environment; $\mathrm{p}=.000$ ). Besides the trait anxiety score is also negatively correlated with D1=Domain 1 (Physical health; $\mathrm{p}=.001$ ), $\mathrm{D} 2=$ Domain 2 (Psychological; $\mathrm{p}=.000$ ), $\mathrm{D} 4=$ Domain 4 (Environment; $\mathrm{p}=.000$ ). However, there is no significant difference in terms of D3= Domain 3 (Social Relationship; state anxiety $\mathrm{p}=.142$ and trait anxiety $\mathrm{p}=.220$ ) and STAI scores. On the other hand, there is positive correlation between the score of BDI and STAI ( $p=.013)$. But there is negative correlation between BDI and quality of life (Domain 1, p=.000; Domain 2, p=.000; Domain 3, p=.005; Domain $4, p=.003$ ). In order to improve the patient's overall health, there is need of holistic approach more specifically intervention from mental health professionals.

\section{REFERENCES}

1. Living with or beyond cancer. Macmillan Cancer Support. Retrieved 2015-07-22.

2. DCCPS: OCS: About cancer survivorship research: survivorship definitions. Office of cancer survivorship of the US national cancer institute. 6 November 2006. Retrieved 30 November 2010.

3. Yang YL, Guo-Yuan Sui, Guang-Cong Liu, et al. The effects of psychological interventions on depression and anxiety among Chinese adults with cancer: a metaanalysis of randomized controlled studies. BMC Cancer 2014;14:956. http://www.biomedcentral.com/14712407/14/956.

4. Heydarnejad MS, Hassanpour Dehkordi A, Solati Dehkordi K. Factors affecting quality of life in cancer patients undergoing chemotherapy. African Health Sciences 2011;11(2):262-270.

5. World Health Organization. The ICD-10 classification of mental and behavioiral disorders: clinical descriptions and diagnostic guidelines. Delhi: A..I.T.B.S. Publishers \& Distrisbutors 2007. 
6. American Psychiatric Association. Diagnostic and statistical manual of mental disorder. 2015; $5^{\text {th }}$ edn.

7. Fallowfield LJ, Hall A, Maguire P, et al. Psychological effects of being offered choice of surgery for breast cancer. BMJ 1994;309(6952):448.

8. Loge JH, Abrahamsen AF, Ekeberg O, et al. Psychological distress after cancer cure: a survey of 459 hodgkin's disease survivors. Br J Cancer 1997;76(6):791-796.

9. Jenkins $\mathrm{R}$, Bebbington $\mathrm{P}$, Brugha $\mathrm{TS}$, et al. British psychiatric morbidity survey. $\mathrm{Br} \mathrm{J}$ Psychiatry 1998;173:4-7.

10. Wells KB, Golding JM, Burnam MA. Psychiatric disorder in a sample of the general population with and without chronic medical conditions. Am J Psychiatry 1988;145(8):976-981.

11. Derogatis LR, Morrow GR, Fetting D, et al. The prevalence of psychiatric disorders among cancer patients. JAMA 1983;249(6):751-757.

12. Massie M, Holland J. Overview of normal reactions and prevalence of psychiatric disorders. In: Holland J and Rowland J, ed. Handbook of psychooncology. Psychological care of the patient with cancer. New York: Oxford University Press 1989;p 273-82.

13. Parle M, Jones B, Maguire P. Maladaptive coping and affective disorders among cancer patients. Psychol Med 1996;26(4):735-744.
14. Devlen J, Maguire P, Phillips $P$, et al. Psychological problems associated with diagnosis and treatment of lymphomas. Br Med J 1987;295(6604):953-957.

15. Leigh S. Myths, monsters, and magic: personal perspectives and professional challenges of survival. Oncology Nursing Forum 1992;19(10):1475-1480.

16. World Health Organization. Recuperado en septiembre 15, 2005. disponible en http://www.who.int/ publications/es/

17. Spielberger CD, Gorsuch RL, Lushene RD. STAI manual. Consulting Psychologist press, Palto Alto, California 1970.

18. Beck AT, Steer RA. Internal consistencies of the original and revised beck depression inventory. J Clin Psychol 1984;40(6):1365-1367.

19. World Health Organization. Geneva programme on mental health whoqol-bref introduction, administration, scoring and generic version of the assessment and generic version of the assessment. 1996.

20. Yang YL, Liu L, Wang Y, et al. The prevalence of depression and anxiety among Chinese adults with cancer: a systematic review and meta-analysis. BMC Cancer 2013;13:393.

21. Aass N, Fossa SD, Dahl AA, et al. Prevalence of anxiety and depression in cancer patients seen at the Norwegian radium hospital. Eur J Cancer 1997;33(10):1597-1604. 